\title{
Title: Synthesis of mono and multidomain YIG particles by chemical coprecipitation or ceramic procedure
}

\author{
Authors: L. Fernandez-Garcia, M. Suarez ${ }^{*}$ J. L. Menendez. \\ Affiliations: Departamento de Materiales Nanoestructurados, Centro de Investigación en Nanomateriales \\ y Nanotecnología (CINN). \\ Principado de Asturias - Consejo superior de Investigaciones Científicas (CSIC) - Universidad de \\ Oviedo (UO). \\ Parque Tecnológico de Asturias, 33428 Llanera, (Asturias), Spain.
}

\begin{abstract}
Yttrium iron garnet powders have been synthesized by chemical coprecipitation using two different precursors, nitrates and chlorides, and by an oxides mixture route. It is shown that depending on the precursors and synthesis conditions used pure yttrium iron garnet powders can be obtained with a mono or multidomain magnetic behaviour. The yttrium iron garnet crystalline structure, as studied by Raman spectroscopy, was already formed after calcination at temperatures as low as $800{ }^{\circ} \mathrm{C}$ when the nitrate precursors were used. However, calcination temperatures of up to $1100{ }^{\circ} \mathrm{C}$ were required to obtain yttrium iron garnet powders when the precursors were chlorides or when the oxides mixture route was chosen. The saturation magnetization of the powders correlates well with the structural characterization: when nitrate precursors were used, the saturation magnetization was already close to the bulk value, $26.8 \mathrm{emu} / \mathrm{cc}$, after calcination at 800 ${ }^{\circ} \mathrm{C}$. However, the saturation magnetization of the powders obtained by the chlorides and oxides mixture routes was close to zero up to calcination temperatures of $1100{ }^{\circ} \mathrm{C}$. Finally, both the chlorides and the oxides mixture routes yield multidomain micron
\end{abstract}

\footnotetext{
* Corresponding autor. Tel.: +34 9859800 58; fax: +34 985265574

E-mail address: m.suarez@cinn.es (M. Suarez)
} 
sized yttrium iron garnet powders, whereas the nitrates route led to monodomain submicron sized powders.

Keywords: Ceramics; chemical synthesis; Ferromagnetic garnets; Oxides mixture; Saturation magnetization 


\section{Introduction}

The development of magnetic particles is an exciting topic both from fundamental and technological points of view. Their fundamental properties, saturation magnetization, magnetic anisotropy, band structure, etc, may be modified not only when their size is driven into the nanometer range, but also their magnetic behaviour: coercive field, superparamagnetic or ferromagnetic behaviour and, in the latter case, monodomain or multidomain state can be tailored with an appropriate choice of the synthesis routes and conditions. From a technological point of view, data processing and magnetic storage where increasingly higher recording densities are demanded have very likely been the main driving force for the increased interest on magnetic nanoparticles. However, nanoparticles become superparamagnetic [1] at finite temperatures for very small sizes, and this is an impairment to the information storage. Besides magnetic data storage, magnetic particles find a wide range of applications: they have been incorporated in electrochemical sensors, used for hyperthermia treatments, drug delivery... In the former case [2], magnetic particles (MPs) of micro- and nanoscale, mimicking the size of molecules in nature, possess interesting characteristics that facilitate the purification and detection of biomolecules in a wide range of samples. In particular, the high surface area and the paramagnetic or superparamagnetic properties of these tiny particles provide an attractive technology platform for the design of electrochemical biosensors. Ferromagnetic particles have also been proposed for hyperthermia treatments [3] in which the magnetic particles are drawn to the site with a magnetic field and an oscillating electromagnetic field is then applied which makes the nanoparticles vibrate and heat up the surrounding tissue. These days, ferrimagnetic garnets are widely used in electronic devices for the microwave region [4] and $\mathrm{Y}_{3} \mathrm{Fe}_{5} \mathrm{O}_{12}$ (YIG) crystals dispersed on glass have been investigated for high-density magnetic or magneto-optical 
information storage [5]. Superparamagnetic particles are also used as contrast agents in MRI applications [6] or in drug delivery $[7,8]$ to drive the drugs to the organs requiring one particular drug without affecting the other organs.

Previous works on the YIG powders have analyzed their synthesis by different routes, controlled their granulometry by changing $\mathrm{pH}$, calcination temperature, calcination times $[9-11] \ldots$ The most common way to produce $\mathrm{Y}_{3} \mathrm{Fe}_{5} \mathrm{O}_{12}$ is the oxides mixture [1214]. However, production of YIG following this process is extremely dependent on the precursors used, particularly on their granulometry, and high calcination temperatures must be used in order to obtain pure YIG powders. Calcination temperatures between 600 and $1200{ }^{\circ} \mathrm{C}$ have been reported [12,13]. Some magnetic properties such as coercive field and initial permeability are strongly dependent on the microstructural aspects, i.e. the synthesis method and the conditions of further annealing and grinding. Much attention was paid to the conventional ceramic methods in order to ameliorate the homogeneity and the density of grains, but this method requires very high temperatures. For this reason, wet-chemical methods of synthesis have been developed in order to obtain homogeneous YIG particles at low temperatures [15-18]. Parameters such as the annealing temperature, precursors, chemical routes, $\mathrm{pH}$ have been studied $[15,15]$.

In this work, YIG particles are synthesized following two different routes: oxides mixture and reverse-strike coprecipitation and three different precursors: chlorides, nitrates and oxides and the evolution of the saturation magnetization is studied as a function of the calcination temperature and correlated to their size and structure. It is shown how an adequate selection of the synthesis route and the synthesis parameters allows obtaining mono or multidomain YIG particles. 


\section{Experimental procedures}

YIG ferrite powders with a stoichiometric composition of $\mathrm{Y}_{3} \mathrm{Fe}_{5} \mathrm{O}_{12}$ were prepared by two different methods: reverse-strike coprecipitation and oxides mixture. $\mathrm{Y}_{3} \mathrm{Fe}_{5} \mathrm{O}_{12}$ prepared by reverse-strike coprecipitation were synthesized using different precursors, iron and yttrium nitrates $\left(\mathrm{Fe}\left(\mathrm{NO}_{3}\right)_{3} \cdot 9 \mathrm{H}_{2} \mathrm{O}(\mathrm{ABCR}, 98.0-101.0 \%)\right.$ and $\mathrm{Y}\left(\mathrm{NO}_{3}\right)_{3} \cdot 6 \mathrm{H}_{2} \mathrm{O}$ (Aldrich, 99.9\%)), respectively, and iron and yttrium chlorides $\left(\mathrm{FeCl}_{3} \cdot 6 \mathrm{H}_{2} \mathrm{O}(\mathrm{ABCR}\right.$, $98 \%$ ) and $\mathrm{YCl}_{3} \cdot 6 \mathrm{H}_{2} \mathrm{O}$ (Aldrich, 99.99\%)), respectively. Iron and yttrium nitrates or iron and yttrium chlorides were mixed with a 5:3 molar ratio. The $\mathrm{pH}$ value was kept constant at 10 by adding ammonium hydroxide solution (Sigma-Aldrich, 28.0-30.0\% in water) due to the fact that it is critical for the control of the chemical homogeneity within the particles. After $24 \mathrm{~h}$ of aging, a gelatinous precipitate was obtained. Then, solvent was removed by centrifugation and subsequently the amorphous gel was freezedried. All powders prepared by using different precursors were burnt at different temperatures in order to achieve a crystalline material. In the oxides mixture the raw materials, $\mathrm{Fe}_{2} \mathrm{O}_{3}$ (Aldrich, $99.9 \%$ purity) with a particle size around $5.0 \mu \mathrm{m}$ and $\mathrm{Y}_{2} \mathrm{O}_{3}$ (Cerac, $99.99 \%$ purity) with a particle size around $9.0 \mu \mathrm{m}$, were mixed in propanol with alumina balls for $1 \mathrm{~h}$ using an attrition mill. The powders were thermally calcined in air between 800 and $1200{ }^{\circ} \mathrm{C}$ for $2 \mathrm{~h}$ to obtain pure yttrium iron garnet.

Thermogravimetric and differential temperature analysis for three products (TGA/DSC Star System, Mettler Toledo) were carried out under air atmosphere at a heating rate of $5^{\circ} \mathrm{C} / \mathrm{min}$ up to $1600{ }^{\circ} \mathrm{C}$ The phase transitions of the heat-treated samples as a function of the temperature were followed by Raman spectroscopy (Jobin Yvon, HORIBA) to determine the crystalline phases of the burnt powders. The average grain size of the powders was characterized by a granulometric analysis (FRITSCH Analysette 22 
MicroTec XT). The hysteresis loops were measured with an alternative gradient magnetometer (AGM, MicroMag ${ }^{\mathrm{TM}}$, Princeton Measurements Corporation).

\section{Results and discussion}

The TG-DTA curve corresponding to nitrate precursors (Fig. 1a), shows a weight loss associated to an endothermic peak between $40-250{ }^{\circ} \mathrm{C}$ corresponding to the dehydration of absorbed water in the powders and the dehydroxylation processes (15\% weight loss). This is followed by a small and sharp exothermic peak around $250{ }^{\circ} \mathrm{C}$ attributed to the evaporation of $\mathrm{NH}_{4} \mathrm{NO}_{3}$ which appears during the synthesis as a byproduct. Another endothermic peak related to the decomposition of the precursors in the oxide compounds is observed between 300 and $400{ }^{\circ} \mathrm{C}$. The sharp exothermic peak at $760{ }^{\circ} \mathrm{C}$ is due to the crystallization of YIG.

Figure $1 \mathrm{~b}$ shows the TG curve corresponding to the chlorides route. There is also a weight loss associated to an endothermic peak between $40-250{ }^{\circ} \mathrm{C}$ corresponding to the dehydration of absorbed water in the powders and the dehydroxylation processes $(20 \%$ weight loss) as in the nitrates route. An exothermic peak related to the crystallization of YIG is observed at $730{ }^{\circ} \mathrm{C}$. Differences in the thermograms corresponding to nitrates and chlorides precursors can be observed, showing a different slope at temperatures over $500{ }^{\circ} \mathrm{C}$. These differences can be attributed to the higher difficulty to remove the halogen compounds than the nitrates, appearing both as a byproduct during the synthesis.

There is no sharp peak observed in the TG curve corresponding to the oxides mixture (Fig. 1c); just a broad exothermic peak starting at approximately $1000{ }^{\circ} \mathrm{C}$ and having a maximum at $1400{ }^{\circ} \mathrm{C}$. Also, a minor weight loss $(3 \%)$ is observed through all the studied temperature range. 
These differences in the TG DTA graphs suggest different behaviours in the synthesis of YIG and, therefore, different possibilities of tailoring the microstructure of the powders. A sharp formation of YIG from the chlorides and nitrates precursors would be expected already at $800{ }^{\circ} \mathrm{C}$ whereas a slow formation of YIG at temperatures over $1000{ }^{\circ} \mathrm{C}$ would be expected in the oxides route.

The structural evolution of the calcined samples has been done by Raman spectroscopy (Fig. 2). Figure 2a shows that in the nitrates route the structure already corresponds to that of YIG after calcination at $800{ }^{\circ} \mathrm{C}$, with well defined peaks in the appropriate intensity relationships. A very different behaviour is observed in Fig. 2b, corresponding to the Raman spectra of the calcined powders from the chlorides route. A structural transition is observed between 1000 and $1100{ }^{\circ} \mathrm{C}$. Below $1100{ }^{\circ} \mathrm{C}$ peaks other than those of YIG are observed. Although, it is difficult to assign these peaks to a precise compound, they resemble very much those of the stoichiometric powder mixture $3 \cdot \mathrm{Y}_{2} \mathrm{O}_{3}: 5 \cdot \mathrm{Fe}_{2} \mathrm{O}_{3}$. In particular, the peak at $1320 \mathrm{~cm}^{-1}$ is characteristic of $\mathrm{Fe}_{2} \mathrm{O}_{3}$. Other peaks at 217, 290 and $400 \mathrm{~cm}^{-1}$ are also characteristic of $\mathrm{Fe}_{2} \mathrm{O}_{3}$ and are well observed at temperatures below $1100{ }^{\circ} \mathrm{C}$. However, the most intense vibration corresponding to $\mathrm{Y}_{2} \mathrm{O}_{3}$ is just present as a broad band at $1060 \mathrm{~cm}^{-1}$ and the second most intense peak of $\mathrm{Y}_{2} \mathrm{O}_{3}$ at $373 \mathrm{~cm}^{-1}$ is not present in the Raman spectrum. This implies that $\mathrm{Fe}_{2} \mathrm{O}_{3}$ has partially reacted with $\mathrm{Y}_{2} \mathrm{O}_{3}$, leading to a low $\mathrm{Fe}_{2} \mathrm{O}_{3}$ compound such as $\mathrm{YFeO}_{3}$. Calcinations at $900{ }^{\circ} \mathrm{C}$ and $1000{ }^{\circ} \mathrm{C}$ do not lead to large structural differences as shown in the corresponding Raman spectra. However, it can be seen that the peak at $290 \mathrm{~cm}^{-1}$ in the powder calcined at $800{ }^{\circ} \mathrm{C}$ shifts to $270 \mathrm{~cm}^{-1}$ at $1000{ }^{\circ} \mathrm{C}$ indicating that the remnant $\mathrm{Fe}_{2} \mathrm{O}_{3}$ is reacting to form YIG. However, it is not until $1100{ }^{\circ} \mathrm{C}$ that the calcined powders fully transform into YIG; the peak at $1300 \mathrm{~cm}^{-1}$ shifts to $1400 \mathrm{~cm}^{-1}$. 
Therefore, it has been shown that even following a reverse-strike precipitation, where an intimate mixture of the cations is achieved before calcinations, the choice of precursors determines the transitions and the calcination temperature required to obtain pure YIG. When the oxides mixture route is chosen, as already mentioned in the introduction, the temperature required in order to obtain pure YIG is strongly dependent on the structural features of the raw oxides, mainly their granulometry. Here, raw materials with particle sizes in the micron range have been used. It can be seen in Fig. $2 \mathrm{c}$ that at $800{ }^{\circ} \mathrm{C}$ the spectrum of the calcined powders is basically that of the stoichiometric mixture prior to calcination. Just a slight peak broadening is observed, which indicates that minor diffusion has taken place at this temperature. At $900{ }^{\circ} \mathrm{C}$ the situation is basically the same, although a minor peak at $275 \mathrm{~cm}^{-1}$, characteristic of YIG, is now observed, indicating that its formation starts at this temperature. At $1000{ }^{\circ} \mathrm{C}$, the peak at $380 \mathrm{~cm}^{-1}$, characteristic of $\mathrm{Y}_{2} \mathrm{O}_{3}$ decreases its intensity whereas the peak at $340 \mathrm{~cm}^{-1}$, corresponding to YIG shows now intensity comparable to the previously mentioned one. Therefore, it is possible to obtain pure YIG at this temperature, as the process is thermodynamically favourable; however, long holding times are required. At $1100{ }^{\circ} \mathrm{C}$, the situation has completely changed: there are no peaks at 380 or $1060 \mathrm{~cm}^{-1}$. A new peak at $630 \mathrm{~cm}^{-1}$ is now present, corresponding to an intermediate phase, probably $\mathrm{YFeO}_{3}$. Finally, after calcination in air at $1200{ }^{\circ} \mathrm{C}$ for one hour, the spectrum corresponding to pure YIG is obtained.

As stated in the introduction, previous works have already dealt with the synthesis of YIG. However, in some of them, the presence of other phases, such as $\mathrm{YFeO}_{3}$ and $\mathrm{Fe}_{2} \mathrm{O}_{3}$ are observed [10] up to high calcination temperatures $\left(1300{ }^{\circ} \mathrm{C}\right)$. In the case of the ceramic method, this is mainly due to the initial granulometry. The larger the grain size, the higher the temperature required to obtain pure YIG. This explains why in Ref. 
[10] the temperature required to obtain pure YIG goes up to $1200{ }^{\circ} \mathrm{C}$ and $2 \mathrm{~h}$ holding time and, in general, the scattering of data in the literature [12-19]. Also, differences in the $\mathrm{pH}$ used during the synthesis may account for the different phases found at the different calcination temperatures. As shown in Ref. [9], an inadequate control of the $\mathrm{pH}$ may lead to precipitation of different phases.

According to Y. Iida et al. [20], nitrate ions as well as sulphate and halogen ions, are known as suppressors of the transformation process in YIG, making the kinetics of phase transformation slower. In the present case and according to the thermogravimetry results, the nitrate ions are easily removed from the product (note the larger weight loss between 200 and $600{ }^{\circ} \mathrm{C}$ ) which makes the phase transition easier since a larger amount of gas is released, thus avoiding agglomeration [21] and leading to a lower temperature for the formation of YIG.

YIG is a collinear ferrimagnet, having two magnetic sublattices, formed by the tetrahedral and octahedral iron ions respectively. The resulting saturation magnetization is equal to the difference in the sublattice magnetizations, corresponding to $5 \mu \mathrm{B}$ per formula unit at $\mathrm{T}=0 \mathrm{~K}$. Deviations in the iron concentration and the tetrahedral and octahedral sites leads to changes in the magnetic moment of the system [22]. All the superexchange interactions, the intrasublattice $\mathrm{J}_{\mathrm{aa}}$ and $\mathrm{J}_{\mathrm{dd}}$, and $\mathrm{J}_{\mathrm{ad}}$, the intersublattice exchange interaction, are antiferromagnetic. Under the influence of the dominant $\mathbf{J}_{\mathrm{ad}}$ the two sublattices are oriented antiparallel resulting in the ferrimagnetism of the YIG. However, the moments of the individual sublattices are ferromagnetically ordered. The strongest magnetic interactions occur in the intersublattice exchange, superexchange interaction, between $\mathrm{Fe}^{3+}$ irons in octahedral and tetrahedral sites through intervening $\mathrm{O}^{2-}$ ions 
The differences in the sintering process also lead to changes in the magnetic behaviour of the powders as a function of their calcination temperature. This way, the powders obtained from the nitrates route show a magnetic moment close to bulk already at $900{ }^{\circ} \mathrm{C}$ calcination temperature. At $800{ }^{\circ} \mathrm{C}$, the magnetic moment of these powders is below its bulk value, although close to it, indicating that the YIG structure is close to having been formed. On the other hand, both the powders obtained from the chlorides route have a very low magnetic moment at calcination temperatures below $1100{ }^{\circ} \mathrm{C}$. At that temperature there is a sharp transition that correlates with the structural transition shown in Fig. 2b and the saturation magnetization corresponding to bulk YIG is then obtained. Analogously, when the oxides mixture route is followed, the magnetic moment at low calcination temperatures is close to zero, even smaller than that of $\mathrm{Fe}_{2} \mathrm{O}_{3}$. When the oxides mixture is calcined at $1100{ }^{\circ} \mathrm{C}$ the bulk YIG saturation magnetization is obtained and remains there after calcination at $1200^{\circ} \mathrm{C}$.

The synthesis routes and the calcination temperatures required to obtain the bulk YIG saturation magnetization lead to different final grain sizes. This way, the nitrates route allows obtaining monomodal distributions of the particle size between 0.5 and 0.7 microns, as a function of the calcination temperature. The chlorides route at $1100{ }^{\circ} \mathrm{C}$ leads to powders with an average particle size of $3 \mu \mathrm{m}$ and agglomerates of up to $20 \mu \mathrm{m}$. Finally, the oxides route leads to powders with an average particle size of $6 \mu \mathrm{m}$ after calcination at $1100^{\circ} \mathrm{C}$. The thickness, $\delta$, of a domain wall is estimated to be [1]:

$$
\delta=\sqrt{\frac{n \times J \times S^{2}}{K \times a}}
$$


where $\mathrm{n}$ is the number of atoms per unit cell, $\mathrm{J}$ is the exchange integral constant, $\mathrm{S}$ the spin, K, the anisotropy constant and a the lattice parameter. Substituting for typical values reported for YIG [Error! Bookmark not defined.,23], the domain wall thickness is around 1-2 $\mu \mathrm{m}$. This way, the powders obtained after the nitrates route will be monodomain, whereas powders obtained after the chlorides and oxides mixture routes will be multidomain. Therefore, by choosing adequately the route and the calcination temperature, it is possible to obtain powders with a monodomain or a multidomain behaviour.

\section{Conclusions}

Oxides mixture and reverse strike precipitation with chlorides and nitrates as precursors have been used and compared in the synthesis of pure YIG powders. The nitrates route allows obtaining single phase crystalline powders at lower temperatures $\left(800^{\circ} \mathrm{C}\right)$ with their saturation magnetization already close to bulk YIG and an average particle size below one micron at low calcination temperatures. On the other hand, the oxides route and reverse strike precipitation with chloride precursors lead to YIG powders with the saturation magnetization corresponding to bulk YIG only over $1100{ }^{\circ} \mathrm{C}$ burning temperature. The average particle size in both cases is over one micron: $3 \mu \mathrm{m}$ for the chlorides route, showing large agglomerates and $6 \mu \mathrm{m}$ average particle size for the oxides route. Therefore, by choosing the adequate synthesis route and the calcination temperature, powders with a mono or multidomain magnetic behaviour can be obtained.

\section{Acknowledgments}


The authors want to acknowledge the Spanish Ministry of Education and Science and UE for funding through project MAT2009-14534-C03-03. One of us, L. Fernandez-Garcia, wants to acknowledge JAE program for $\mathrm{PhD}$ grant. 


\section{Figures}

760

(a)

250

370
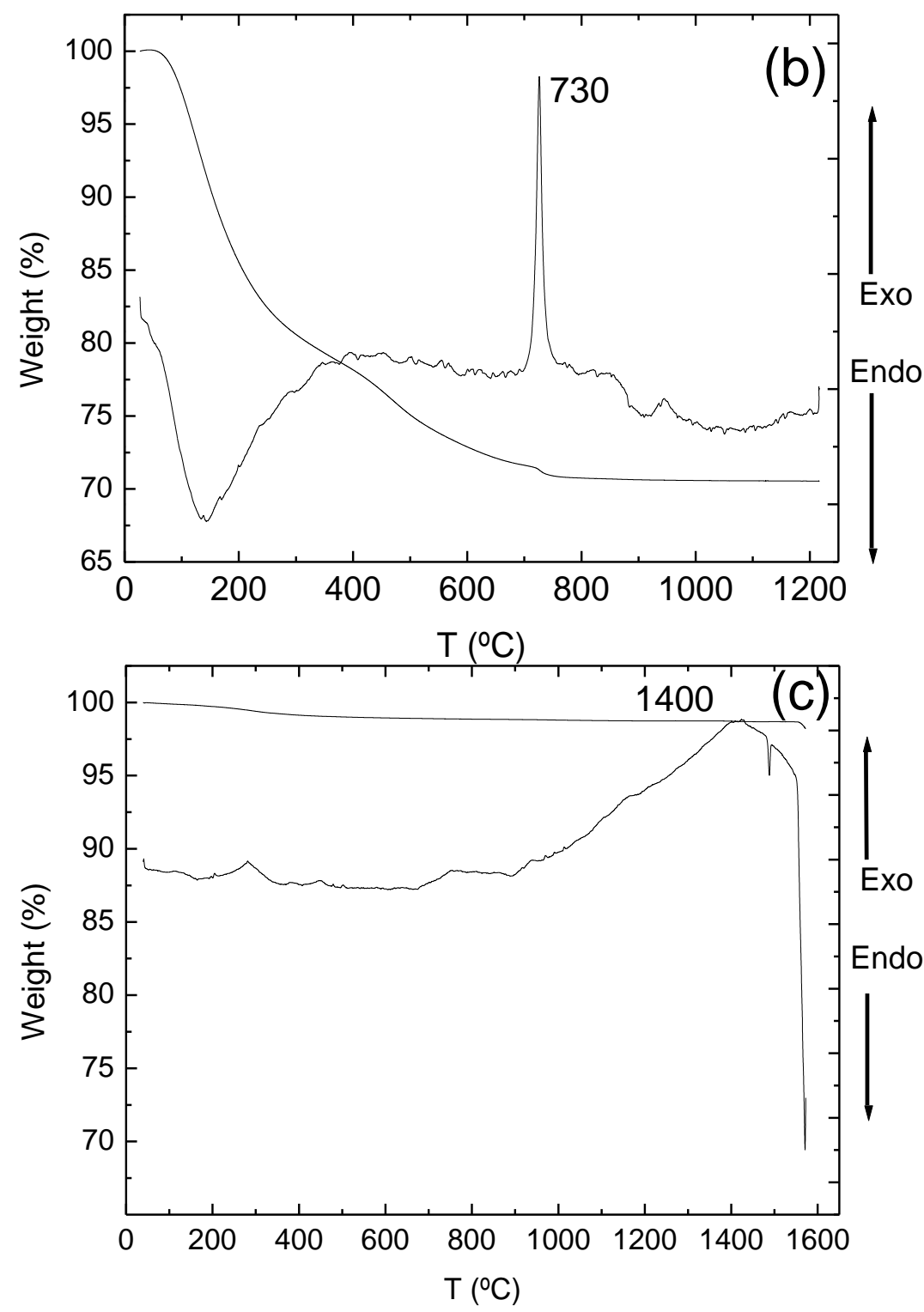

Fig. 1 


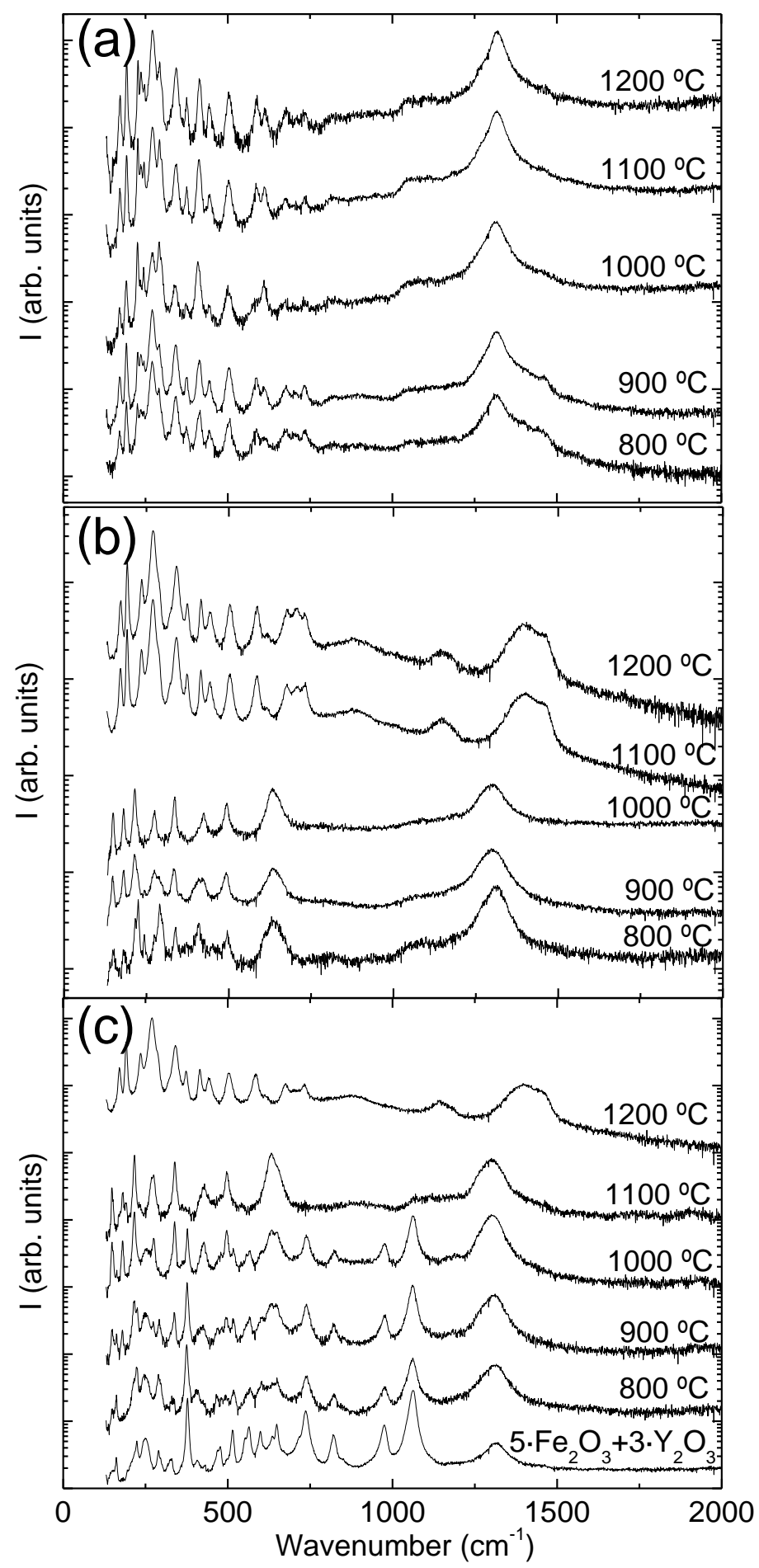

Fig. 2 


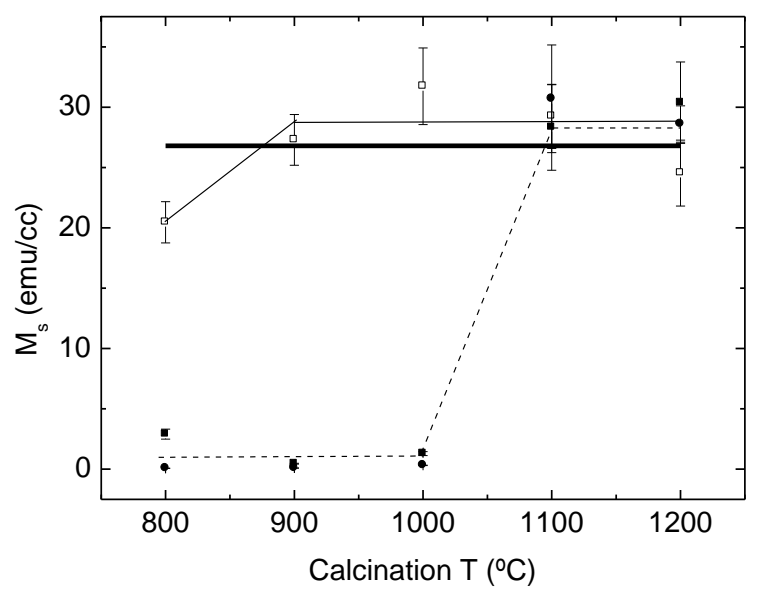

Fig. 3 


\section{Captions}

Fig 1. Thermogravimetry curves for the different routes studied: nitrates (a), chlorides (b) and oxides (c).

Fig 2. Raman spectra of powders calcined at temperatures between 800 and $1200{ }^{\circ} \mathrm{C}$ for the nitrates (a), chlorides (b) and oxides (c) routes.

Fig 3. Saturation magnetization as a function of the calcination temperature. Full squares (circles) correspond to the chlorides (oxides) route, open squares to the nitrates route. Lines are guides for the eye. 


\section{References}

[1] S. Chikazumi, The Physics of Ferromagnetism, second ed., Oxford University Press, 1997.

[2] M. Hsing, Y. Xu, W. Zhao, Electroanalysis 19 (2007) 755-768.

[3] R. Hergt, S. Dutz, R. Müller, M. Zeisberger, J. Phys: Condens. Matter. 18 (2006) S2919-S2934.

[4] R. D. Sanchez, J. Rivas, P. Vaqueiro, M. A. Lopez-Quintela, D. Caeiro, J. Magn. Magn. Mater. 247 (2002) 92-98.

[5] S. Taketomi, C. M. Sorensen, K. J. Kabunde, J. Magn. Magn. Mater. 222 (2000) 54-64.

[6] L. Josephson, Biological and Biomedical Nanotechnology, Springer, US, 2006.

[7] M. Arruebo, R. Fernández-Pacheco, M. R. Ibarra, J. Santamaría, Nano Today. 2 (2007) 23-32.

[8] J. Dobson, Drug Dev. Res. 67 (2009) 55-60.

[9] P. Vaqueiro, M. P. Crosnier-Lopez, A. Lopez-Quintela, J. Solid State Chem. 126 (1996) 161-168.

[10] M. Ristic, I. Nowik, S. Popovic, I. Felner, S. Music, Mater. Lett. 57 (2003) 2584-2590.

[11] P. Vaqueiro, M. A. Lopez-Quintela, Chem. Mater. 9 (1997) 2836-2841.

[12] N. R. Holmquist, C. F. Kooi, R. W. Moss, J. Am. Ceram. Soc. 44 (1961) 194-196.

[13] A. Sztaniszlav, E. Sterk, L. Fetter, M. Farkas-Jahnke, J. Labar, J. Magn. Magn. Mater. 41 (1984) 75-78.

[14] P. Grosseau, A. Bachiorrini, B. Guilhot, Powder Technol. 93 (1997) 247-251.

[15] P. Vaqueiro, M. A. Lopez-Quintela, J. Rivas, J. M. Greneche, J. Magn. Magn. Mater. 169 (1997) 56.

[16] M. Rajendran, S. Deka, P. A. Joy, A. K. Bhattacharya, J. Magn. Magn. Mater. 301 (2006) 212-219.

[17] M. I. Yanovskaya, T. V. Rogova, S. A. Ivanov, N. V. Kolganova, N. Ya. Turova, J. Mater. Sci. Lett. 6 (1987) 274-276.

[18] P. Vaqueiro, M. A. López-Quintela, J. Rivas, J. Mater. Chem. 7 (1997) 501-504.

[19] E. V. Tkaehenko, P. P. Pazdnikov, V. M. Zhulovskii, A. Ya. Neiman, A. G. Shapovalov, M. N. Rivkin, T. G. Veselovskaya, Neorg. Mater. 16 (1980) 2034.

[20] Y. Iida, A. Towata, T. Tsugoshi, M. Furukawa, Vib. Spectrosc. 19 (1999) 399-405.

[21] G. Xu, X. Zhang, W. He, H. Liu, H. Li, R. I. Boughton, Mater. Lett. 60 (2006) 962-965.

[22] M. Pardavi-Horvath, A. Thavendrarajah, P. E. Wigen, J. Magn. Magn. Mater. 119 (1993) 193-204.

[23] M. Niyaifar Ramani, M. C. Radhakrishna, A. Hassnpour, M. Mozaffari, J. Amighian. Hyperfine Interactions, 184 (2008) 161-166. 
760

(a)

250

370
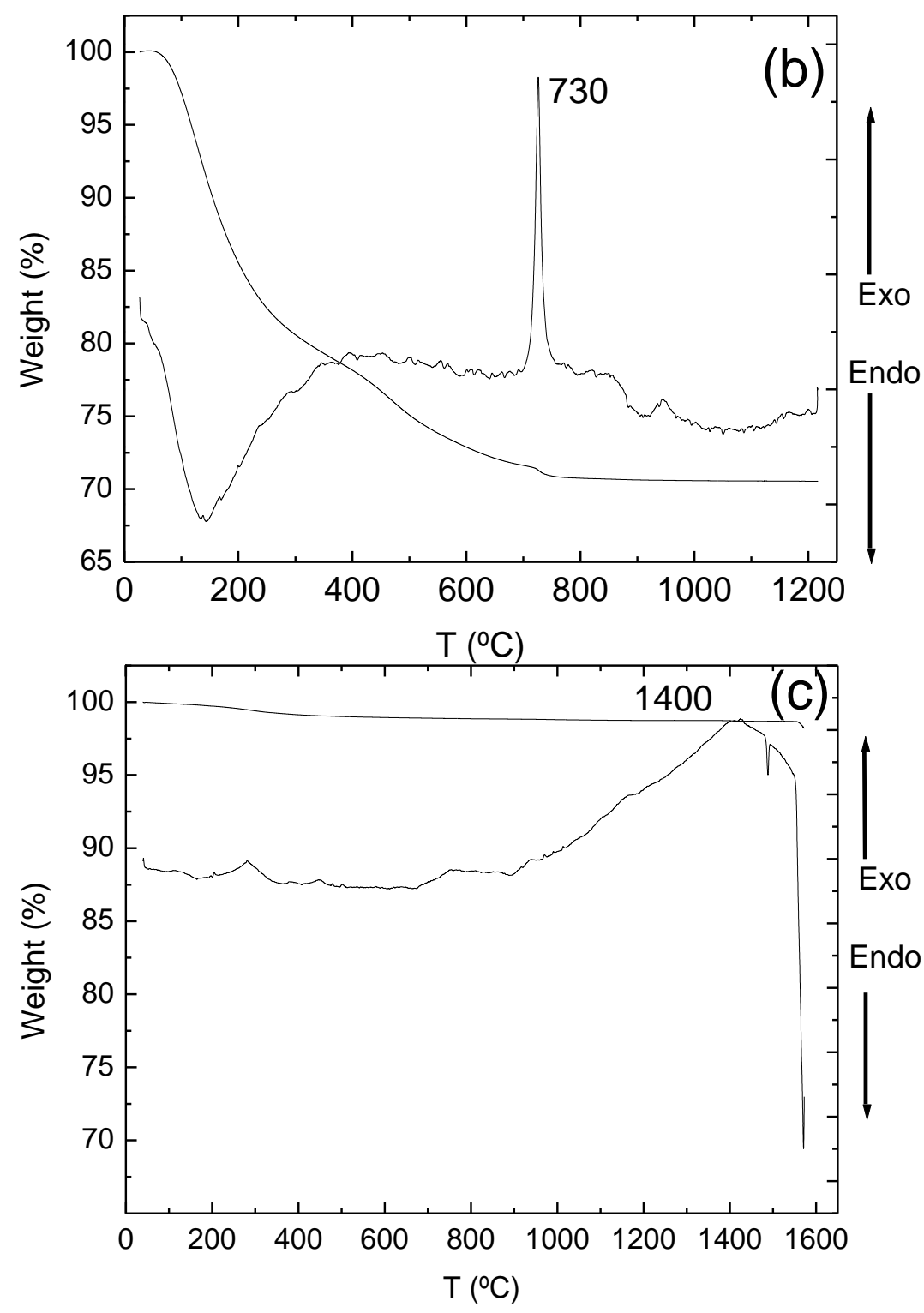


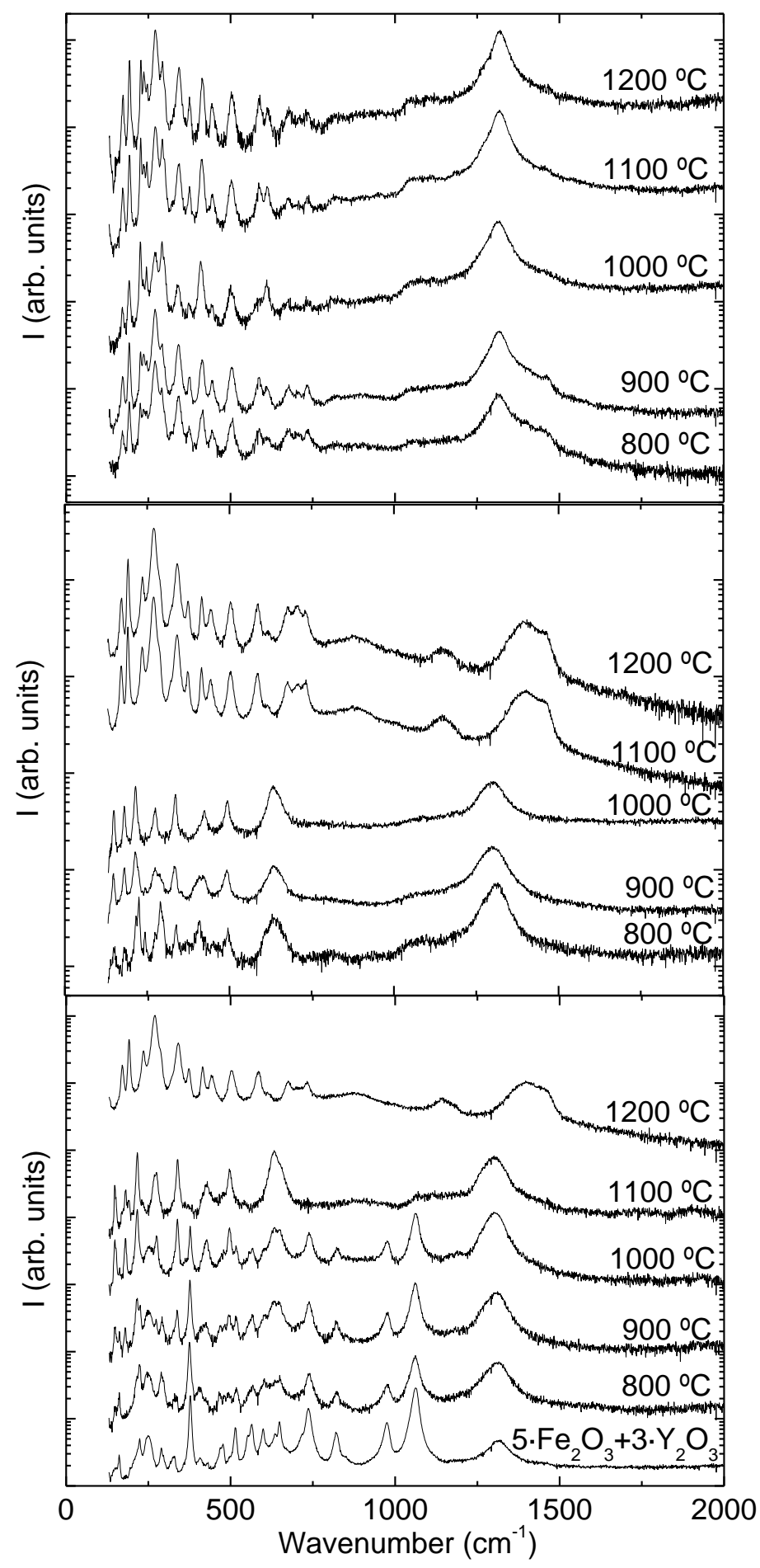


Figure(s)

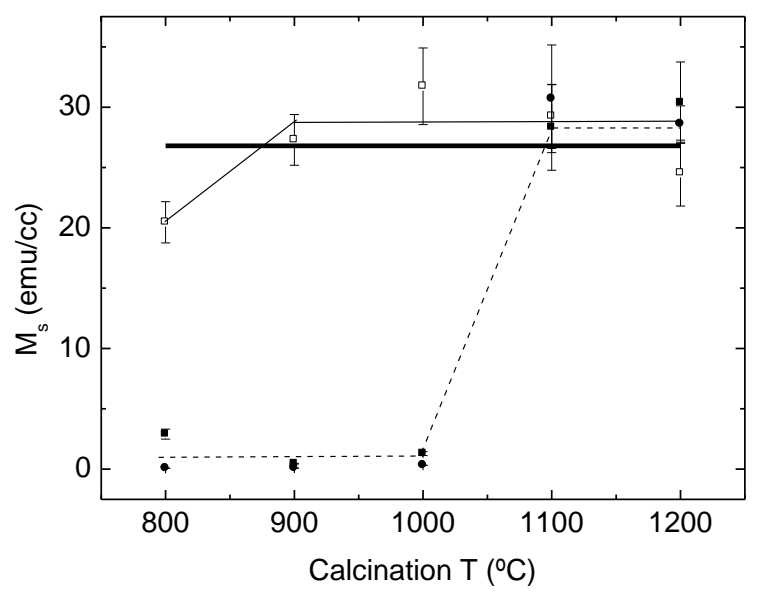

Calcination $\mathrm{T}\left({ }^{\circ} \mathrm{C}\right)$ 